\title{
ACLARANDO EL CLARO. UNA REFLEXIÓN SOBRE “LA DOMESTICACIÓN DEL SER" DE SLOTERDIJK
}

\author{
Jonathan Triviño CuéllaR* \\ doi:10.11144/Javeriana.uph35-70.acrs
}

\section{RESUMEN}

Ante al fracaso del humanismo y de su tarea de domesticación del hombre, Sloterdijk piensa las circunstancias de nuestro mundo desde el punto de vista antropotécnico, es decir, una perspectiva que enfatiza el desarrollo técnico del hombre, revelando las implicaciones para la condición humana de la sociedad tecnológica contemporánea, saturada de información, pero despreocupada con el tipo de pensamiento reflexivo que caracterizó las meditaciones filosóficas del pasado. Repensar al hombre desde un enfoque biocultural y basado en procesos implica el rechazo, una vez más y con una profundidad renovada, del esencialismo humanista que impregnaba la filosofía antes de Heidegger.

Palabras clave: Sloterdijk; claro; domesticación; humanismo; esencialismo; antropotécnica.

* Pontificia Universidad Javeriana. Bogotá, Colombia.

Correo electrónico: jtrivino@javeriana.edu.co

Para citar este artículo: TriviÑo CuélLAR, J. (2018). Aclarando el claro. Una reflexión sobre "La domesticación del Ser" de Sloterdijk. Universitas Philosophica, 35(70), pp. 173-205. ISSN 01205323, ISSN en línea 2346-2426. doi:10.11144/Javeriana.uph35-70.acrs 


\title{
CLARIFYING THE CLEARING. A REFLECTION ON SLOTERDIJK'S "DOMESTICATION OF BEING"
}

\author{
Jonathan Triviño CuÉllar
}

\begin{abstract}
Faced with the failure of humanism and its task of man-taming, Sloterdijk thinks about the circumstances of our world from the standpoint of anthropotechnics, that is, a perspective that emphasizes man's technical development, unveiling the implications for the human condition of contemporary technological society, saturated with information but unconcerned with the kind of reflective thought that characterized the philosophy of the past. Rethinking man from a biocultural and process-driven approach involves the rejection, once again and with renewed depth, of the humanist essentialism that pervaded philosophy before Heidegger. Keywords: Sloterdijk; clearing; domestication; humanism; essentialism; antropotechnics.
\end{abstract}




\section{La dignidad del claro es intangible \\ Sloterdijk}

\section{Resonancias: lo monstruoso}

Uno de los problemas QUe enfrenta Sloterdijk, a partir de su respuesta a la Carta sobre el humanismo de Heidegger, es el uso de términos comúnmente utilizados con referencia a los animales, como el de 'cría' (Züchtung) y 'domesticación', que lleva a sus críticos a ver en ellos una evocación de la terminología nazi ${ }^{1}$, como parece ser el caso de la crítica de Habermas.

El origen de las acusaciones de Habermas se encuentra en los espejismos -en los fantasmas revividos del nacionalsocialismo- que sigue ocupando vastas zonas del inconsciente colectivo alemán, de modo tal que campos semánticos enteros se encuentran bloqueados para un uso inteligente (Vásquez Rocca, 2009b, p. 193).

Sloterdijk aparentemente hace uso de la jerga nacionalsocialista, pero lo que sus críticos no pueden entender es que son los nazis los que no le dieron un significado adecuado a realidades propias de lo humano, en tanto que, entre otras cosas, el hombre también es animal (racional). Parece como si la comprensión aristotélica estuviese, más que errada, proscrita, como si después del nacionalsocialismo estuviera vedado hablar del carácter de animal del animal racional. Sin embargo, lo que Sloterdijk está reivindicando es una comprensión del hombre desde un horizonte antropotécnico ${ }^{2}$ que le permite vislumbrar mejor la realidad

1 Ello también se debe a sus claros vínculos con un pensador como Arnold Gehlen, que fue miembro del Partido Nacionalsocialista y luego un crítico acérrimo del movimiento estudiantil del 68.

2 Pensar antropotécnicamente es pensar al ser humano como el producto de una serie de técnicas aplicadas sobre sí mismo que le permiten venir al mundo como ser-en-el-mundo. Para Sloterdijk 'claro' y 'devenir humano' son dos expresiones que designan lo mismo. Estas técnicas le permiten al hombre la salida del entorno natural (el Umwelt de von Uexküll*) y la apertura (Lichtung) al mundo (Welt).

* El biólogo alemán Jakob von Uexküll (1864-1944) fue uno de los precursores de la etología junto con Konrad Lorenz. En sus estudios propiamente biológicos, Uexküll describe los procesos fisiológicos que permiten la interrelación entre el organismo y el ámbito exterior al sujeto, 
actual a partir de las técnicas de domesticación que han atravesado la historia humana desde su pre-hominización (vinculado con el entorno animal) hasta su estancia estática en el claro (vinculado con la monstruosidad), que lo han conducido hasta un hoy tecnificado y atravesado por los mass media y la tecnología, rebasando el horizonte del proyecto humanista. Es decir, más allá de estas polémicas debe "examinarse la verdadera intención de Sloterdijk al interrogar por los fundamentos de la domesticación y la educación humana” (Vásquez Rocca, 2009b, p. 194).

Las reflexiones filosóficas del siglo XX, sobre todo después de 1945, ante la perplejidad de lo monstruoso se han abocado a pensar lo que Sloterdijk llama las grandes circunstancias: las guerras, las bombas de destrucción masiva, las políticas de extermino del hombre por el hombre, la pérdida de un sentido de lo humano, la técnica biológica y genética, etc., es decir, a pensar la situación impensable a la que el hombre ha llegado en medio de un mundo que prometía, en el proyecto moderno, un progreso de la razón y de mejores condiciones de vida y bienestar. Pensar en estas grandes circunstancias es en lo que se han ocupado movimientos filosóficos y artísticos que se alimentan de la filosofía de finales del siglo XIX y principios del siglo XX. Todos estos movimientos del pensamiento y de producción intelectual se dedicaron a pensar las situaciones límite de la existencia humana. Situaciones que es urgente pensar aún hoy. Estas reflexiones, después de la década de los setenta y frente a una sociedad de consumo desenfrenado, dieron como resultado un pensamiento posmoderno en medio de un ambiente neomediocre donde los asuntos fundamentales parecen no contar para el hombre y donde la unidad entre Ser y verdad ya no es posible:

La posmodernidad coincide, en primera instancia, con la imposibilidad de alcanzar una verdad última (ya sea científica, filosófica o religiosa) sobre la realidad. En una palabra, el sentido de la realidad se fabuliza. Y esta fabulización

el cual es vivenciado desde la perspectiva del mundo interior del organismo (percepciones, sensaciones). En este sentido y de manera general, el concepto de entorno (Umwelt) se refiere al circuito significativo que se da entre los estímulos externos y el mundo interior del organismo, el cual permite su desenvolvimiento funcional en el entorno vital que le corresponde (Méndez, 2013, p. 177). 
de la díada realidad-verdad trae consigo la caída de la fe en los grandes relatos que, por lo menos hasta mediados del siglo XX, quisieron mostrarse como orientadores de la existencia humana (Méndez, 2013, p. 179).

De esta forma el proyecto ilustrado se ve fracturado y fragmentado en múltiples reflexiones filosóficas que dejan de lado el pensar en situaciones límite, porque ya parece imposible pensar las grandes circunstancias en un mundo de consumo cabalgante, mediocre, trivializado e indiferente.

Hoy, después de las grandes circunstancias de las dos grandes guerras, se hace urgente pensar de nuevo el lugar del hombre en el mundo, pues lo que está en juego es "una nueva definición del hombre" (Sloterdijk, 2011, p. 108). Esa nueva definición, es decir, volver a pensar el hombre, se impone pues la enormidad del hombre aún no ha sido suficientemente pensada, enormidad que tanto Nietzsche como Heidegger habían vinculado con la mayor cercanía del hombre a los dioses que a los animales. La enormidad en clave heideggeriana estaba vinculada con lo titánico y olímpico, con esa lucha de los dioses, pero en Sloterdijk (2011) eso divino se ha convertido en monstruoso: "lo monstruoso ha ocupado el lugar de lo divino" (p. 107). Comprender al hombre hoy demanda pensar en la monstruosidad de su origen y de su apertura al claro, de su estar ek-stático en el mundo:

En torno al hombre, todo se convierte en mundo, mas no porque el hombre sea un dios de empírico conocimiento [...], sino porque su posibilidad es monstruosa y porque la capacidad del hombre para la verdad se revela como su dote más inquietante y peligrosa. Lo ontológicamente monstruoso consiste en que, en torno a un ser no divino, todo se convierte en mundo (Sloterdijk, 2011, p. 108).

Esto es lo que Heidegger llama el claro, la relación monstruosa del hombre con la verdad y su venir al mundo en tanto configurador de mundo. "El término claro (Lichtung) es parte de la lógica y la poesía de los monstruoso" (Sloterdijk, 2011 , p. 108). De ahí la pertinencia de pensar la diferencia ontológica en tanto que los animales no vienen al mundo, sino que son paridos y están en medio de una jaula ontológica determinada y limitada (Umwelt); en cambio el hombre se halla tanto dentro como por fuera de este entorno y establece mundo, se abre al mundo, está en el mundo (Welt): "Lo que aquí se designa como mundo debe, 
pues, concebirse como un circunmundo deslimitado" (p. 107). Mundo es mundo humano, es mundo para el hombre, es domesticación del Ser.

Lo monstruoso se debe pensar hoy en día ante la monstruosidad de la técnica más allá de la experiencia nuclear del siglo pasado; debe pensarse en el orden de los avances de la técnica en un ámbito biológico, que "amenazan" con desmontar todo lo que hasta ahora parece que tenemos claro sobre el hombre. Por tal razón, debemos repensar al hombre antropotécnicamente desde su advenimiento al mundo. Lo que Sloterdijk está haciendo en "Domesticación" es precisamente pensar las condiciones, implicaciones y manifestaciones de la técnica biológica con respecto a la autocomprensión del hombre actual. Eso es monstruoso. Es una gran circun-stancia (estar ek-stático en el mundo). Son técnicas que muchas veces van en contra del hombre mismo. En el mundo actual, "los desarrollos del conocimiento científico-técnico superan, con mucho, la capacidad racional del ser humano de prever sus efectos" (Méndez, 2013, p. 180). La técnica actual es una técnica de lo monstruoso, de lo enorme. Dos fechas parecen recordarnos esta monstruosidad de la técnica nuclear y biológica: 1945 , con las bombas de Hiroshima y Nagasaki, donde la humanidad pudo ver el claro, y 1997, con la clonación genética de Dolly y hoy con las promesas de clonación humana y edición genética. Estos acontecimientos nos llevan a pensar al hombre como un producto en un mundo de producción, un mundo técnico donde el hombre se autocomprende como gestor de sí mismo y ya no como una creación divina. La posmodernidad es pensar la muerte de Dios y el origen no divino del hombre.

Ante esta situación, Sloterdijk nos propone volver a los grandes problemas y para ello se hace necesario pensar al hombre en una perspectiva circular, que lo mire en su génesis y vuelva al hombre de hoy, pero ya no desde un horizonte ontológico de orden heideggeriano, sino desde un horizonte onto-antropológico. "Las enormes y crecientes capacidades ofrecidas por las tecnologías obligan a repensar, de nuevo, la cuestión del ser humano” (Mussi, 2007, p. 45 [traducción del autor]).

Así, no es posible entender a un pensador como Sloterdijk sin sus esenciales vínculos con la antigua pregunta que vuelve a entrar en escena de las reflexiones filosóficas, sobre todo a partir de las célebres obras, aunque marginadas y ciertamente olvidadas, de personajes como Ernst Cassirer, Helmuth Plessner, 
Arnold Gehlen y Max Scheler'; se trata de la pregunta por el lugar del hombre en el cosmos. Sloterdijk rescata la pertinencia de volver a plantearse la pregunta por el hombre, "[...] pero combinando los avances de la biología con la perspectiva de las ciencias del espiritu” (Castro-Gómez, 2012, p. 65). Su intención es profundizar de una forma adecuada las complejas relaciones del ser humano con la técnica a partir de un diálogo, ya no solo con Gehlen, sino también con Heidegger, identificando los aciertos y los problemas de su visión en su temprano diagnóstico de lo humano de 1929 y 1946. Ya en "Reglas para el parque humano" Sloterdijk nos sorprende con su lenguaje un tanto mordaz e hiriente al referirse al ser humano, que en un primer momento nos causa rechazo e incomprensión, pues estamos acostumbrados a un lenguaje más "sofisticado" para referirnos al hombre. Lo mismo pasa en La bumillacción por las máquinas; en ambos textos podemos encontrar un diagnóstico de la evidente decepción que le causa el proyecto humanista, un escándalo contemporáneo que demuestra que ese proyecto, inaugurado por Platón, resultó un fracaso.

El humanismo no es otra cosa que una visión mentirosa del hombre, que hace derivar su "dignidad" de lo que en realidad son productos culturales bien tardíos. Lo que el humanismo olvida es que el hombre ha pasado la mayor parte de su vida sobre este planeta habitando en espacios que nada en absoluto tienen que ver con las culturas superiores (Sloterdijk, 2006). De ahí la pertinencia de su respuesta a la Carta sobre el humanismo de Heidegger, pues ambos, desde puntos de

3 Scheller (1994) sostiene: "[e]n ninguna época de la historia ha resultado el hombre tan problemático para sí mismo como en la actualidad" (p. 17). Siguiendo este hilo de pensamiento, Cassirer (1967) afirma: "[e]sta es la extraña situación en que se encuentra la filosofía moderna. Ninguna edad anterior se halló en una situación tan favorable en lo que respecta a las fuentes de nuestro conocimiento de la naturaleza humana. La psicología, la etnología, la antropología y la historia han establecido un asombroso bagaje de hechos extraordinariamente rico y en crecimiento constante. Se han mejorado inmensamente nuestros instrumentos técnicos para la observación y la experimentación, y nuestros análisis se han hecho más agudos y penetrantes. Sin embargo, no parece que hemos encontrado el método para dominar y organizar este material. Comparado con nuestra abundancia, el pasado puede parecer verdaderamente pobre, pero nuestra riqueza de hechos no es necesariamente una riqueza de pensamiento" (p. 24).

4 Esta es precisamente una de las tesis fundamentales de la propuesta antropológica de Gehlen (1993): "[1]a pregunta de si no es posible elaborar una representación del hombre reuniendo otra vez esos dos aspectos, o sea, elaborar una imagen que explique tanto su actividad cultural de ser biológico concebido como tal y su estructura biológica” (p. 28). 
vista distintos, abordan el problema del hombre, distanciándose de las infructíferas reflexiones del humanismo para dar razón del lugar del hombre en un mundo tecnificado como el nuestro.

Para comprender qué es el hombre, se hace necesario volver a plantear la pregunta por su lugar en el mundo mediante un ejercicio genealógico, al modo nietzscheano, que nos remita a la antropogénesis (Castro-Gómez, 2012, p. 66). Se trata de una reflexión de antropología histórica desde la incipiente formación de los invernaderos pre-humanos hasta el advenimiento monstruoso y peligroso en el claro del mundo en perspectiva onto-antropológica, por más extraño que esto nos pueda sonar:

Intentaré, en lo que sigue, mostrar que la meditación de Heidegger del éxtasis existencial también es relevante para comprender la crisis actual de la autodefinición biológica de los hombres, esa crisis en las formas de acceder los hombres a los hombres para las que mi discurso Reglaspara el parque bumano ha introducido la expresión antropotécnica (Sloterdijk, 2011, p. 100).

\section{Domesticación}

EN UN PRIMER MOMENTO EL CONCEPTO ClaVe es, sin lugar a duda, el de domesticación. Domesticar es reducir, acostumbrar a la vista y compañía del hombre al animal fiero y salvaje; sin embargo, en este caso es la domesticación misma del hombre por el hombre en el cual acontece y se muestra el Ser. De esta forma, el concepto de domesticación puede ser ambivalente. Por un lado, tiene una dimensión de corte negativo, pues refiere a la relación entre domesticadores y domesticados, tal como lo aclara Nietzsche $e^{5}$ y que Sloterdijk recoge

5 Nietzsche (2003): “[p]ues quería enterarse de lo que entretanto había ocurrido con el hombre: si se había vuelto más grande o más pequeño. Y en una ocasión vio una fila de casas nuevas; entonces se maravilló y dijo: ¿Qué significan esas casas? ¡En verdad, ningún alma grande las ha colocado ahí como símbolo de sí misma! [...] Y Zaratustra se detuvo y reflexionó. Finalmente dijo turbado: ¡Todo se ha vuelto más pequeño! Por todas partes veo puertas más bajas: quien es de mi especie puede pasar todavía por ellas sin duda, ipero tiene que agacharse! Oh, cuándo regresaré a mi patria, donde ya no tengo que agacharme ¡donde ya no tengo que agacharme ante los pequeños!'” (p. 241). 
en "Reglas"; y, por otro, una dimensión que he querido denominar positiva de la domesticación, que se encuentra ahora en el texto que nos ocupa en clave antropotecnicogenética.

Si la pregunta en "Reglas" era sobre qué podía hoy domesticar al hombre una vez que el proyecto humanista había fracasado, la pregunta en "Domesticación" girará en torno al papel de la domesticación en el paso de la apertura al claro y, por ende, a la aparición del ser humano. La perspectiva de Sloterdijk va más allá que la nietzscheana, pues recoge el problema del hombre desde los estadios prehumanos y la hominización de camino al claro. Sloterdijk aborda el problema en el mundo primitivo en clave antropogenética, es decir, quiere pensar el tránsito de un entorno natural al mundo mediado por el distanciamiento causado por la técnica, un entorno artificialmente producido. La función de este mundo artificial no es otra que la crianza y domesticación de seres humanos. Así, pues, la domesticación no tiene solo el carácter netamente negativo de un proyecto fracasado del mundo griego hasta nuestros días.

En la diferencia Umwelt/Welt, la diferencia ontológica, en el proceso de prehominización y hominización encontramos la clave de esta dimensión positiva de la domesticación que le permite al hombre abrirse paso al claro. De esta manera, Sloterdijk también dirige su crítica en contra del empequeñecimiento determinista del hombre propio de la burda concepción positivista y biologicista (evolucionista) que da por sentado el lugar del hombre, olvidándolo, y no aclara su advenimiento al claro del Ser. La venida del ser humano al claro es un evento singular. Sloterdijk, de la mano de Heidegger y su análisis del éxtasis existencial del Dasein, está pensando la peligrosidad de la donación del mundo al hombre. Hay mundo, hay claro, hay hombre, hay técnica, hay Ser, ya que "el claro no se puede pensar sin su origen tecnógeno" (Sloterdijk, 2011, p. 146) y, por ende, pensar al homo humanus es pensar la domesticación del Ser. "En la línea de Foucault y Deleuze, Sloterdijk considera que es necesario comprender al hombre

6 A este respecto, Vásquez Rocca (2009a) afirma: “[1]a filosofía de Nietzsche se configura así a partir de la reflexión en torno al problema de la humanidad y la animalidad, es decir, se articula como un intento de ir más allá del humanismo entendido como un esfuerzo de domesticación del hombre en el que se pretende desinhibir su condición animal (fracasando en el proceso). De allí la importancia de la discusión en torno al estatuto biopolítico del hombre, debate en el que se insertan autores como Peter Sloterdijk y Giorgio Agamben” (p. 4). 
desde la conciencia de que es un producto, un efecto de programaciones y adiestramientos" (Pipó Comorera, 2003, p. 2), esto es, de domesticación:

La expresión "antropotécnica" responde a un teorema claramente perfilado de la antropología histórica: según él, "el hombre" es en el fondo producto, y solo puede ser entendido -dentro de los límites del saber actual- examinando analíticamente sus métodos y relaciones de producción (Sloterdijk, 2011, p. 100).

Así, lo que hace nuestro filósofo en este ensayo es pensar al hombre a partir de una historia genealógica de la hominización donde el aparecer del hombre acontece como un evento único en el mundo; puesto que no se pude hablar de mundo en cuanto tal, previo a la aparición del hombre; de ahí que hable de prehumano y pre-mundo en su genealogía para no presuponer al ser humano en ningún sentido previo a su advenimiento al mundo por la técnica (Bühlmann, 2007, p. 12).

En este sentido, el hombre solo se puede entender como un producto, como resultado de la producción y de la domesticación:

La pregunta por las producciones de las que ha resultado el hecho hombre adquiere un significado que no puede separarse de la pregunta por la "verdad" de este ente. En efecto, "el hombre" es, como especie y como matriz de posibilidades de individualización, una magnitud, que jamás puede darse en la pura naturaleza y que solo ha podido constituirse por efecto de prototécnicas espontáneas y en "convivencia" con cosas y animales, en prolongados procesos de formación en lo que pronto se echa de ver una tendencia paranatural (Sloterdijk, 2011, p. 100).

La pregunta es, pues, tanto por la verdad del hombre como por el claro. Esa verdad se muestra y "acontece" en el claro que advino al hombre gracias a la técnica y la prototécnica de los prehomínidos.

El texto empieza con una cita de las lecciones de 1929 de Heidegger, Los conceptos fundamentales de la metafisica. Mundo, finitud y soledad:

[1]as siguientes reflexiones pueden entenderse como una variación sobre la frase de Heidegger: "El entendimiento vulgar no ve en el mundo, atrapado como está en el puro ente", una frase que en su laconismo no solo expresa la desacreditada y no fácil de entender "diferencia ontológica", sino que también 
hace recordar la guerra, nunca finalizada desde los tiempos de Platón, entre la filosofía y el pensamiento “ordinario” (Sloterdijk, 2011, p. 93).

La variación no es ni mucho menos una variación vulgar del texto, sino en cierto sentido una transformación fundamental que nos permite entender la domesticación constitutiva del hombre en su proceso de venir al mundo en tanto ek-sistente, estar abierto al claro del Ser. Viéndonos con las cosas, ocupados haciendo cosas, presuponemos el mundo, pero no lo pensamos en cuanto tal, no nos fijamos en lo que da, esto es, no pensamos la donación del Ser, que nos remite al asombro heideggeriano: hay Ser, se da el Ser. La pregunta del 27 del Heidegger de Ser y tiempo por el Ser, y su pregunta por el mundo del 29, nos abren la posibilidad de volver a pensar lo que por estar tan cerca no pensamos: la donación de mundo en su totalidad. Esta primera cita va ligada a otra de la Carta sobre el humanismo, donde afirma el filósofo de Messkirch (Heidegger, 2000): "[p]ensar la verdad del Ser significa al mismo tiempo pensar la humanitas del homo bumanus" (p. 4), es decir, pensar cómo el hombre vino al mundo como humanus. El Ser se da en el hombre que está-en-el-mundo. Su estar-en es la diferencia ontológica que ahora piensa Sloterdijk en clave evolutiva antropotécnica, mas no evolucionista.

El prehomínido en su medio ambiente salvaje va configurando progresivamente un entorno que lo condiciona (circunmundo, Umwelt), cambiando el escenario en el cual se encuentra en pro de unas condiciones mejores para su seguridad y estabilidad, es decir, abriéndose al claro (Lichtung). Esta comprensión nueva de nuestro filósofo frente a la comprensión ontológica y antiantropológica heideggeriana, se puede denominar onto-tecno-antropología. Es, si se quiere, una perspectiva evolutiva antropotécnica, que tiene en cuenta la imaginería metafórica y el pensamiento visual que conforman el humano llegar-a-elmundo (Jongen, 2011, p. 199). Este camino hacia el claro se da gracias a los progresos pequeños y, al mismo tiempo, gigantes (monstruosos) de la técnica y del salir de un entorno condicionante y determinado a una configuración nueva de mundo. Los procesos de cambio, mejora, modificación del entorno, son los primeros rasgos pre-antropotécnicos que encontramos en el prehomínido, son rasgos de domesticación, de llevar al espacio del domus, del interior, las circunstancias biológicas externas, es decir, es una optimización del interior frente a las amenazas del exterior. Agudizando un poco nuestra mirada, podemos 
reconocer ya entonces que homínido es sinónimo de antropotécnica, es decir, no hay humano sin técnica, de tal forma que no es un apéndice o un rasgo externo del hombre habérselas con las cosas y modificarlas técnicamente. Los hombres vienen al mundo relacionándose no solo con los otros, sino con las piedras que devienen herramientas, con las plantas, con los animales, esto es, en medio de una relación polivalente con su entorno (Sloterdijk, 2005) ${ }^{7}$. La historia de esta cohabitación con elementos cuyo estatuto ontológico no ha sido suficientemente aclarado, que Heidegger quiso establecer de alguna forma en sus lecciones del 29 con la diferencia ontológica, es el desafío del pensamiento de Sloterdijk, que está pensando dicha diferencia desde la antropotécnica.

La crítica de Sloterdijk va en contra de todas aquellas concepciones del mundo y de la cultura que entienden al hombre como algo dado y no como un proceso de modificación, adaptación y domesticación productiva del prehomínido al homo humanus. De esta forma, la exposición sloterdijkiana, que él mismo denomina bellamente fantasía filosófica, se centra en mostrar cómo, en cierto sentido, podemos afirmar que, sin su salida al claro, sin su ser hombre en cuanto hombre, el prehomínido era "inexistente", en el sentido heideggeriano de la existencia ekstática del ser-en-el-mundo. Mundo es mundo humano y, por ende, no hay claro sin el hombre, ya que solo con el advenimiento del hombre como tal "el mundo pudo aclararse como mundo" (Sloterdijk, 2011, p. 101). El hombre es resultado de unos procesos de domesticación y de producción que dieron paso a la posibilidad de la aparición del hombre como un acontecimiento único en la historia y que miles de años después desembocaría en las grandes culturas. El humanismo no puede pensar ni de lejos este proceso de producción en el sentido amplio del término, del hombre en el mundo, pues presupone al hombre en cuanto tal y no ve su proceso de antropogénesis: "[a]hora se trata de ver que también la situación fundamental, aparentemente irreductible, del hombre, denominada ser-enel-mundo y caracterizada como existencia, como un salir fuera, al claro del Ser, es el resultado de una producción" (Sloterdijk, 2011, p. 100).

En este orden de ideas, podemos reconocer que en el presente escrito el filósofo de Karlsruhe nos conduce a caminar-pensar analítico-reflexivamente junto

7 En este punto Sloterdijk está de acuerdo con el rechazo heideggeriano de la dicotomía sujeto-objeto de la filosofía y de la supremacía del alma (espíritu) sobre el cuerpo de orden platónico-cristiano. 
con él acerca del hombre configurador de mundo y sus procesos de domesticación, análisis que el horizonte humanista y positivista no pudo comprender al situarse en perspectivas reduccionistas del mismo. "La premisa decisiva del siguiente ensayo es la suposición de que la historia del hombre debe entenderse como el drama silencioso de sus configuraciones" (Sloterdijk, 2011, p. 103). Las configuraciones del hombre le permiten abrirse al mundo, esto es, sin domesticación el mundo no sería mundo y, por ende, no se hubiese aclarado el claro, no hubiera salido el hombre de su ocultamiento "inexistente"; no habría venido al claro ek-stático de la existencia. Explicar al hombre desde una visión terrena del homo sapiens, y no desde explicaciones ontológicas superiores, tales como las dadas por las omnicomprensiones sagradas teológicas, requiere ver al hombre en su condición de ek-sistente, esto es, del hombre como formador y configurador de mundo. No es que el mundo sea previo al advenimiento del hombre, sino que el mundo es mundo para el hombre. Es un mundo aclarado.

\section{Del Ser. Claro (Lichtung): el lugar del peligro}

Como ya hemos anotado, tanto "Reglas" como "Domesticación" son textos sumamente polémicos, no solo por los conceptos y términos utilizados por nuestro filósofo para referirse al ser humano, sino por las implicaciones onto-antropológicas que su propuesta filosófica tiene para comprender al hombre de hoy. Su pensamiento es ciertamente un diálogo con los grandes pensadores del siglo XX y al mismo tiempo una novedad controversial que despierta un gran interés, debido a que está poniendo en escena de nuevo al hombre desde las realidades más cercanas y cotidianas que configuran nuestro mundo, como es el caso de la técnica y sus monstruosos avances. Uno de esos elementos polémicos de su propuesta es que la técnica, y con esta los avances de producción humanos que nos han absorbido hoy, no es ni mucho menos un fenómeno del mundo contemporáneo, sino que la pregunta por la técnica es "la pregunta humanista por excelencia, que Sloterdijk busca pensar, en el surco de la clave pastoral heideggeriana -la cuestión de la domesticación del hombre por el hombre, que pone al desnudo el paradigma tradicional humanista-" (Bordeleau, 2007, p. 92). Sus reflexiones se amplían y desarrollan mejor en la reconocida trilogía, Esferas. Allí, uno de los aspectos fundamentales que ocupa a Sloterdijk es que toda la 
vida social tiene lugar en determinadas configuraciones espaciales. No se puede comprender la vida social humana sin un arraigo espacial determinado. En estas esferas espaciales es donde el hombre devino homo humanus. La reflexión de Sloterdijk sobre la técnica es sobre todo una reflexión sobre el estatus del ser humano, más que sobre la tecnología misma, reflexión que se hace bajo la forma de una fantasía filosófica (Mussi, 2007, p. 45).

Para Sloterdijk estos entornos, esferas, determinados siempre ofrecen protección o, mejor aún, inmunización frente a las amenazas externas del entorno (Borch, 2013, p. 151). Esto implica que para él el surgimiento de la vida humana está esencialmente determinado por entornos espaciales específicos transformados y configurados como una protección e inmunización frente a las inclemencias del mundo. Es decir, el prehomínido modifica el entorno y eso permite la venida al claro del homínido que climatiza un mundo para él, esto es, domestica el Ser técnicamente. En ese aislamiento artificial-técnico es donde viene el hombre al mundo, al claro del Ser. El prehomínido, y luego el hombre, establece límites y crea espacios nuevos que conocemos como hogares, casas, espacios de habitación donde los grupos se salvaguardan del entorno y de esta forma trasforman el lugar de la desinhibición animal en una inhibición pre-humana y posteriormente humana. Son límites espaciales que enmarcan una nueva esfera que posteriormente será el espacio del domus (casa). Llevar las amenazas del exterior a la seguridad e inhibición del interior es hacer de un espacio del habitar una domes-ticación (relativo a o relacionado con la casa) del ser espacio-temporal.

En este sentido la domesticación del Ser nos lleva a pensar ya no solo la temporalidad del proyecto inicial heideggeriano, sino ahora también junto con él, el espacio relativo a la casa donde habita el hombre. Ese espacio, fuera de la reducción a las tres dimensiones usuales con la cual el entendimiento vulgar comprende el espacio, se vincula con el clarear de un claro en donde viene a la luz el hombre, en donde el hombre deviene como hombre en cuanto tal:

El concepto de espacio que aquí entra en juego es notoriamente un concepto no trivial, no físico y no geométrico, puesto que, como muestra la oscura observación de Heidegger, tiene que ser más antiguo sobre todo que la tridimensionalidad que no es familiar, con lo cual se representa la geometría las mediciones espaciales el sistema de lugares" (Sloterdijk, 2011, p. 112). 
El único que habita la casa del Ser es el hombre que viene al claro en la transformación técnica de su entorno. La técnica hace posible "una distancia con la naturaleza que prepara una habitación (domus, casa) protegida de la naturaleza" (Zin, 2014, p. 1). Estamos en ese plano donde hay principal y necesariamente técnica configuradora de mundo y aperturizadora de mundo aclarado. En este sentido podemos decir que técnica es domesticación y advenimiento del hombre al mundo.

Claro y hominización son dos expresiones de lo mismo (Sloterdijk, 2011, p. 104), es decir que devenir humano y claro son dos expresiones que se refieren a la misma realidad. Ese proceso de devenir, de hominización, se muestra en esa posibilidad del hombre de salir de las determinaciones de su entorno y configurar un espacio en el cual habite alejado de los peligros externos, espacio que nosotros llamamos apertura de mundo. Aunque Sloterdijk reivindica a Heidegger, también es cierto que le hace una fuerte crítica que consiste, fundamentalmente, en el hecho de que su concepción del hombre no piensa su carácter biocultural.

Como Sloterdijk muestra en "La domesticación del Ser", la idea de vivienda (habitación) está sobre todo ligada a la ocupación de un suelo, y especialmente al claro de un espacio que debe ser equipado. La idea de claro viene de la noción heideggeriana de Lichtung que, según Derrida (1995), evoca a su vez la khôra platónica del Timeo, que hace referencia a la matriz, seno, vientre, plano, de todas las dimensiones y como receptáculo de todo lo que deviene (pp. 20-22). Es decir que el claro es el espacio-tiempo donde el hombre viene al mundo y el Ser se muestra. Es en este sentido que se debe mirar la esfera primitiva de "vientre" como "nodriza del devenir" de dimensiones y direcciones. Este receptáculo es el espacio de incubación y de climatización o, si se quiere, parque autógeno humano, donde se produce la domesticación o proceso de hominización técnica. En este sentido, para entender la condición de domesticación, las esferas se comprenden como sobres, membranas ontológicas entre interior y exterior que dan paso al advenimiento del homo humanus: "[1] as esferas pueden describirse como lugares de resonancia interanimal e interpersonal en los que la manera en que los seres vivientes conviven adquiere una fuerza plástica" (Sloterdijk, 2011, p. 112).

Independientemente de toda metáfora, estas esferas pueden ser vistas como una casa de cristal o de burbujas, en la medida en que establece unas condiciones climáticas especiales, que constituyen el fondo ontológico del tránsito del 
pre-humano al humano. El entorno -la garantía de la vida orgánica, esa región o suelo envolviéndonos- es ante todo una jaula, una burbuja, un anillo (Teyssot, 2013 , p. 243). Este toma la forma de un mundo medio localizado entre la proyección orgánica de la vida animal y la proyección del homínido -vía al claro- en el mundo. Esta esfera es topológicamente intermedia. Por un lado, está el (animal) ser rodeado por un anillo (circunmundo), un recinto, una frontera; por el otro lado está un (humano) ser capaz de un acto ek-stático que se supera a sí mismo por una apertura a un mundo intermedio -haciendo un claro-. Esta esfera es intermedia, además cumple el rol de intermedianidad (Teyssot, 2013, p. 243). Esta intermedianidad es la que Sloterdijk trata de pensar tanto en Esferas como en "Domesticación", en el horizonte de una fantasía filosófica con miras a aclarar el claro del Ser, esto es, con miras a mostrarnos su comprensión del hombre como producto y producción al mismo tiempo.

El ser humano (clearing-Lichtung) en el pensamiento sloterdikiano es un ser compuesto básicamente por dos dimensiones esenciales:

1. Una historia natural de la serenidad, la cual expone la manera como el hombre pudo convertirse en un ser abierto al mundo. 2. Una historia social de los amansamientos que pone en evidencia la manera como los hombres se recogen (en el sentido de crear cultura, pero también de refrenarse, de contenerse) para corresponder al todo (Méndez, 2013, p. 176).

Con el fin de pensar estas dos dimensiones y para entrar en la situación formadora del hombre, Sloterdijk se adentra en cuatro mecanismos, de cuya cooperación resulta el advenimiento del hombre al claro del Ser, ya que "ninguno de ellos podría él solo motivar la hominización, y aún menos la salida al claro, pero en su sinergia actúan como un ascensor hacia el éxtasis humano" (Sloterdijk, 2011, p. 115). Se trata de los mecanismos de insulación, de exclusión corporal, de pedomorfosis o neotenia, y de transferencia.

\subsection{LA INSULACIÓN}

EN PRIMERA INSTANCIA, ES IMPORTANTE ACLARAR QUE INSULACIÓN PrOViene del término latino insula (isla), lo que nos da ya la clave perfecta para comprender en qué consiste este mecanismo. Insulación es un aislamiento que da paso a la creación de espacios interiores. Este mecanismo es el más primitivo de nuestra 
sinergia y fue planteado por primera vez por Hugh Miller. La insulación es una especie de islas antropogenéticas o antropósferas que permiten la creación de un espacio nuevo de resguardo. "La insulación es la agrupación de individuos cuyas márgenes son una especie de muro que aísla (relativamente) el grupo de las presiones ambientales, liberando entonces la presión de este entorno en el grupo" (Mussi, 2007, p. 49). Es necesario un clima insular que salvaguarde a sus habitantes de las penurias, por ejemplo de la Sabana africana (van Tuinen, 2011, p. 9). Debe haber habido un ambiente altamente modificado que conduzca a sus habitantes a estar en una matriz, de tal manera que esto permita que un 'mundo' aparezca.

"De este efecto de invernadero de primer grado se benefician particularmente, entre los animales gregarios y nómadas, las madres y sus crías, puesto que pueden desenvolverse en un clima de menor peligro y reducidas exigencias de adaptación" (Sloterdijk, 2011, p. 113). Ello permite una relación más intensa entre madres e hijos, que de una u otra forma nos lleva a comprender el tránsito de cómo apareció en el mundo por primera vez un infante. Este nuevo espacio climatizado gracias a unos refinamientos lujosos del prehomínido logra una salvaguarda interesante en la medida que la distancia le permite al prehumano generar un lugar preontológico a la casa, un prehogar. Ese lugar del calor y de la protección, ese efecto de invernadero, girará más en torno a los infantes que a los adultos, lo que nos lleva a reconocer que es la venida al mundo de los niños y no solo la de los adultos la que "modela la sociedad humana como ninguna otra [...]. Los niños transforman con sus demandas muchas -si no todas- de las actividades de los adultos" (en Sloterdijk 2011, p. 116). Las exigencias del bienestar de la prole moldean, transforman y configuran nuevos espacios que darán paso al domus.

\subsection{LA EXCLUSIÓN CORPORAL}

EL SOLO MECANISMO DE INSULACIÓN NO NOS PERMITE PENSAR sino en estadios primitivos de aislamiento y climatización animal, de ahí que se haga necesaria una reflexión en torno a una transformación corporal próxima a la humana de los prehomínidos vinculados al claro. En este punto es cuando la venida de la mano al mundo juega un papel central en el horizonte antropogenético de la comprensión antropotécnica en la obra de Sloterdijk. La primera vez que un 
homo technologicus tomó una piedra con su mano marcaría una diferencia sustancial con respecto a las acciones animales. La mano va intrínsecamente vinculada con el advenimiento del hombre al mundo. Una vez que la pata se transforma en mano, las cosas devienen cosas-para. En este punto Sloterdijk dialoga con Paul Alsberg, pues fue él quien dio la clave de comprensión antropogenética con sus agudos análisis sobre la exclusión corporal que fundamentalmente se encuentra con la tecnificación de cosas en herramientas.

Cuando por primera vez un prehomínido tomó una piedra y la arrojó con determinado fin técnico, la mano entró al mundo. Es decir, hay un distanciamiento de la naturaleza en el uso que se hace de la piedra porque hay un fin marcado que permite entender una clave causal entre el lanzamiento de una piedra y su fin que es derribar, golpear, lastimar, etc., con el propósito de mejoramiento de las condiciones climáticas del prehumano. Este fin del lanzamiento observado por el protohombre nos conduce al descubrimiento de la primera forma de teoría del mundo, ya que hay una proyección, un proyecto, una anticipación de lo que va a ocurrir al arrojar la piedra. Hay un uso causal y no meramente accidental de una piedra que deviene útil-para. Con ello se abren más los pequeños hoyos del entorno que se habían abierto con la insulación. Es, si se quiere, una hiperinsulación técnica, no meramente adaptativa, sino configuradora, climatizadora: "[e]1 mecanismo de la supresión del cuerpo se hace posible por el resultado y, por así decirlo, la exageración del primer mecanismo, la insulación" (Mussi, 2007, p. 49). No es ni mucho menos una mera sofisticación de un prehomo, sino que en el uso de una cosa como útil ocurre un camino o más bien un salto ontológico fundamental, pues los usos de las piedras como herramientas son las primeras luces del claro aclarando la venida del hombre como hombre al mundo, ya que "con esta primera acción de la mano se abre en la naturaleza el nicho ontológico del hombre" (Sloterdijk, 2011, p. 117). Este nicho devendrá domus, de ahí que la antropogénesis sea esencialmente una técnica de domesticación, es decir, la apertura de un espacio ontológico donde el hombre fuera hombre por primera vez.

Así, podemos darnos cuenta de que el hombre comprende algo de lo que él es si piensa su vínculo ontológico con la piedra como útil, como "ser-a-la-mano" $(\mathrm{Zu}$ handensein), si queremos expresarlo con la bella terminología heideggeriana. "La piedra no expresa al hombre; le da una oportunidad de salir al claro” (Sloterdijk, 2011, p. 117). Sin la piedra como útil no hay advenimiento del hombre al claro 
tal y como tuvo lugar históricamente. Con el uso de la piedra encontramos la primera fase de la configuración de mundo humano en cuanto tal. De esta forma, pasamos de un entorno al mundo de la vida, un mundo configurado por la mano del hombre, por la técnica. Este paso es lo que hemos llamado hoyo (abertura) en el entorno natural: "[e]l homínido produce los primeros agujeros y grietas en el anillo del circunmundo cuando, al golpear o arrojar algo, deviene autor de una técnica de la distancia que a su vez repercute en él mismo" (Sloterdijk, 2011, p. 117). Repercutir en él mismo significa abrirse al mundo. En este sentido el hombre viene de la piedra, abriendo paso a la prototécnica como litotécnica y, con ello, a la domesticación del Ser. "Una falla (grieta) entre el hombre y el medio ambiente, un claro, un mundo nació" (Mussi, 2007, p. 50). El hombre nace, viene al mundo por la técnica, esto es, "la bestia se convierte en un ser humano a través del uso de instrumentos que él mismo genera” (Jacques, 2007, p. 32).

En la mano del hombre que usa objetos encontramos una exoneración del contacto corporal, una distancia con las realidades amenazantes del entorno, una producción y de medios de producción, siendo la piedra como herramienta el primero de todos. Hay producción, autoproducción, medio de producción y producto, es decir, hay trabajo y con este la corrección e incorrección de lo que se proyecta hacer. Surge así una visión del éxito de lo que se quiere producir, es decir, de la acción en el arrojar, cortar, tallar, pulir, etc. Así, notamos una primera comprensión de la acción referida al éxito: "[1]a acción supone el éxito, y el éxito remite a la acción que lo produjo” (Sloterdijk 2011, p. 119).

En este punto es importante aclarar que el arrojar, golpear o cortar del protohumano no son tan solo un arrojar, un golpear o un cortar, sino que estas acciones técnicas con determinados fines sofisticados corresponden al primitivo mundo, un mundo incipiente aclarándose como tal, que se restringía al espacio hasta donde nuestras piedras lograran llegar. Una vez se arroja una piedra con cierta intención, una vez que la piedra es tallada para determinada tarea, el mundo no es más el mismo (Mussi, 2007, p. 51). El mundo humano llegaba hasta donde la técnica llegara; por eso hoy en día no hay espacio para lo absolutamente natural, pues todo se comprende técnicamente, mundo es tecnomundo, mundo configurado: "los límites de mis lanzamientos son los límites de mi mundo" (Sloterdijk, 2011, p. 118). Y ¿acaso hoy entendemos de límites en relación con la intervención de la mano del hombre? 
Este espacio de valoración del éxito de la acción o en su defecto de no éxito de la producción es una apertura al claro del mundo con implicaciones ontoantropológicas esenciales. En primer lugar porque este espacio donde acontece la manipulación de objetos, su transformación y uso, es el claro mismo en sus primeros haces de luz y la aparición de la verdad, ya que "los efectos de golpes, lanzamientos y cortes crean un lazo entre éxito y verdad, que en marcos culturales superiores puede estirarse, pero nunca romperse" (Sloterdijk, 2011, p. 119). Es en cierto modo el claro del Ser que viene en la o por la mano del hombre. "Este gesto fundador, que produce la distancia y el claro, que produce el espacio libre, es el origen de la aventura humana, que por lo tanto se fusiona con aventura técnica" (Mussi, 2007, p. 51). El claro del Ser es así, desde el principio, el espacio de intervención técnica en las cosas, un lugar de observación del éxito (verdad) y de la comprensión de un horizonte de las acciones. Un horizonte que se va ampliando hasta nuestros días. Este horizonte le da a todo lo existente una síntesis última:

"[a] partir de aquí podrá desarrollarse en las primeras culturas superiores el concepto clásico de Ser; éste designa y engloba la sustancia a la vez patente y latente, parcialmente alcanzable, pero últimamente inalcanzable, que es común a todas las cosas (Sloterdijk, 2011, p. 120).

En la conjunción de estos dos mecanismos podemos entrever la primera apertura al claro en la evaluación del éxito que también tendrá lugar posteriormente en el ámbito del lenguaje y su relación con la verdad, ya que la verdad acontece tanto en la imagen como en la frase acertada. En el lenguaje, ya sea por gritos, gestos y frases sensibles, se da una acción con miras al éxito. Así, "el paralelismo entre éxitos materiales de las acciones y declaraciones acertadas se hace cada vez más estrecho" (Sloterdijk, 2011, p. 120) y con ello se hace progresivamente más evidente el distanciamiento del circunmundo y la apertura al mundo humano. En este sentido hay una exclusión corporal, un distanciamiento que permite unas nuevas dinámicas de uso de las cosas y de refinamientos que antes el animal prehomínido no se daba. Se entra al espacio de lo lujoso, que le permite al hombre configurar mundo más que adaptarse al circunmundo animal. En esto radica, pues, la fundamental diferencia ontológica en el claro del Ser.

En este momento es importante aclarar que Sloterdijk no está pensando el Ser al modo de la contemplación heideggeriana, sino lo que está pensando es 
más bien el modo como el Ser apareció y, por tanto, la aparición del hombre en el mundo por la técnica. "Sloterdijk muestra que por esta historia tecnológica es que la técnica revela el origen del hombre en tanto hombre” (Mussi, 2007, p. 51). Al modo de una revelación prometeica de la finitud humana y de las posibilidades del hombre en tanto que es ser-en-el-mundo, el hombre se descubre habitador y configurador de mundo técnicamente y en ello descubre también que su origen no es divino, sino terreno y, por ende, finito. De este modo, no solo con "el uso de las herramientas, el hombre constituye un 'mundo', sino más aún lleva a cabo la fabricación de su propio ser” (Jacques, 2007, p. 31). La técnica revela el hombre al hombre. Así, la espacialidad se muestra como la forma esencial de la existencia humana, en el sentido amplio del término que hasta aquí hemos tratado de pensar.

\subsection{PEDOMÓRFOSIS O NEOTENIA}

ESTE TERCER MECANISMO ES EL MENOS EVIDENTE en la historia evolutiva, pero de unas implicaciones notables en la hominización. La evolución humana tiene un elemento estético fundamental unido al perfeccionamiento cognitivo del hombre para producir y establecer el espacio donde él es. Es evidente el perfeccionamiento estético y cognitivo del prehomínido al homo sapiens, no solo por sus habilidades y su uso de las cosas como herramientas, sino también por el embellecimiento de la figura humana, su erguimiento, su alejamiento de las formas primates, el despejamiento del rostro, etc., que se deben a un cambio genético sin el cual no se hubiese dado el paso a la hominización. Una característica fundamental de los homínidos es su continua infantilización. La decadencia causada por el lujo del hábitat de protección es una infantilización (neotenia) notable que permite dos cosas: un adelantamiento del nacimiento y una postergación de la madurez. De una gestación de casi dos años se pasó a una gestación de menos de la mitad del tiempo; de la misma forma se pasó de un tiempo de infancia corto a una infancia dependiente más prolongada y de alguna forma menos autosuficiente, debido a los espacios de invernadero y climatización que modificaron genéticamente a los habitantes de estos espacios.

Así, la evolución genética se ve afectada por los cambios técnicos de los dos primeros mecanismos. "En efecto, una característica sobresaliente de los grupos 
sapiens en evolución es la intensificación sin parangón de la infantilidad: intensificación acentuada por la aportación de rasgos fetales mantenidos en la apariencia adulta" (Sloterdijk, 2011, p. 124). Este cambio evolutivo genético va ligado a ese quinto mecanismo que Sloterdijk intencionalmente dejó de lado por la magnitud y complejidad del mismo, a saber, el mecanismo cerebralización. El aumento de la masa del cerebro y de las capacidades cognitivas humanas junto con la insulación y la exclusión corporal permitieron que el hombre viniera al mundo como autoproducto en un proceso evolutivo de producción. Nótese la sinergia, la cooriginariedad, la coevolución de los cuatro mecanismos hasta ahora mencionados, que, guardadas las distancias, se relacionan con la aperturidad (Erschlossenheit) heideggeriana, el hombre como ente iluminado, abierto al claro.

Los mecanismos descritos dan paso, pues, a un espacio de habitación del hombre que denominamos recinto, la "casa del Ser". Residir es habitar, morar con otros, configurando un lugar adecuado, esto es, climatizado y aislado de las amenazas del mundo. Para Sloterdijk, el recinto es el espacio de advenimiento al claro, es una incubadora abierta socialmente compartida, lograda gracias al distanciamiento técnico del hombre con respecto al entorno. "Pero solo los medios técnicos refinados de tipo comunicativo y simbólico son apropiados para ordenar y climatizar el espacio interior así creado. La incubadora es el espacio inteligente que el lenguaje y la atención vivifican" (Sloterdijk, 2011, p. 128).

En este sentido, la antropotécnica toma así la forma de una domesticación, es decir, "una cría sistemática de los seres humanos por los seres humanos" (Jacques, 2007, p. 33); toma la forma de una producción del hombre sobre sí mismo y sobre las cosas, que lo distancia de su entorno en los mecanismos aquí descritos y le permite abrirse al mundo en el claro del Ser. El hombre configura un espacio ontológicamente nuevo que llamamos casa. De esta forma, la afirmación heideggeriana de que el lenguaje es la casa del Ser, en Sloterdijk se convierte en el espacio es la casa (domus) del Ser: "[d]e esto se sigue que el lenguaje solo es la segunda casa del ser: una casa dentro de esa dimensión promotora y demandadora de casas que aquí con distintas acentuaciones denominamos el buen armazón, el recinto, el invernadero, la incubadora, la antroposfera y, en ocasiones, simplemente esfera" (Sloterdijk, 2011, pp. 128-129). De tal forma que el hombre antes de ser estático al modo heideggeriano, tuvo que ser doméstico, tuvo que primero 
habitar técnicamente un espacio y configurarlo progresivamente como lugar de habitación, como domus. De ahí que Sloterdijk (2011) sostenga: "[s]u habitar y su éxtasis significan lo mismo; la constitución esférica de su permanecer 'en el mundo' lo hace capaz de existir consigo mismo 'fuera'” (p. 130).

Por tanto, en esa apertura al mundo encontramos con mayor claridad la diferencia ontológica entre el animal y el hombre abierto al mundo. El hombre no solo biológicamente tiene notables diferencias evolutivas con respecto al animal, sino que en su modo de estar en el mundo está abierto al Ser y recibe mundo, esto es, habita y forma mundo. El estar fuera del hombre le da la posibilidad de recibir la donación de mundo que da el Ser, ya que "el Ser es la instancia donadora de mundo, y el hombre es el receptor que, al recibir el ente, está atento al emisor $^{8}$, el cual, sin embargo, nunca puede presentarse como ente" (Sloterdijk, 2011, p. 133). De esta forma volvemos al principio con la cita de Heidegger de que el entendimiento vulgar jamás piensa el mundo al estar atrapado en lo ente. En este sentido, Sloterdijk está pensando la circunstancia más importante de todas: hay mundo para el hombre, pero este mundo en el claro se nos muestra y se nos oculta al mismo tiempo; de ahí que pensar el fenómeno del mundo dado al hombre en su venida al mundo sea la gran circunstancia, ya que pensar el mundo es pensar al hombre y su ser en el mundo. Así, el sentido de pensar en el Ser aún oculto, que aún queda por pensar, es lo que Sloterdijk denomina clarificación del claro.

\subsection{LA TRANSFERENCLA}

En eSTE ÚlTimo meCANismo SLOTERDijK está pensando un concepto clave, cual es el de mensaje. Por ello, uno de sus interlocutores será el sociólogo alemán Niklas Luhmann. Junto con los refinamientos ontológicos y evolutivos del hombre en su éxtasis aclarado, no desaparecen las amenazas, sino que otras amenazas surgen y, por ende, la presión del exterior se transforma para el hombre. Hay una amenaza ante la seguridad climatizada del interior formada por el homínido. Con el surgimiento del lugar del habitar humano, nace también la amenaza

8 En palabras de Heidegger, escucha el Ser porque hay Ser y se da el Ser. 
ante este espacio hiperinsulado. La sofisticación tiene su precio, lo mismo que el embellecimiento y la salida al claro. "Ahora se ven, en los varios sentidos de la palabra, desnudos a merced de la devastación del exterior. Ello hace que para ellos sea tanto más importante la posibilidad de recurrir, después de los colapsos, a un repertorio de recuerdos y rutinas que permitan una repetición, de alguna manera modificada, de estados anteriores de orden y de integridad" (Sloterdijk, 2011, p. 135). Lo anterior quiere decir que un nuevo mecanismo de inmunización ante las amenazas externas y ahora internas surja y le permita al hombre continuar en el mundo formándolo y transformándolo. Este mecanismo es la transferencia, que consiste en una inmunología simbólica y de carácter psicosemántico que le permite al hombre seguir existiendo históricamente.

La transferencia consiste en una serie de recursos rituales, de orden religioso, psicológico, mítico, que recurren a situaciones anteriores a la catástrofe y devastación, y que ya no solo le vienen en un orden natural, sino también en un orden humano de otros grupos sociales que se atacan mutuamente. Con este recurso se busca que, ante la nueva, extraña y extrema circunstancia, se moldee la nueva realidad con cualidades de las situaciones pasadas que le dan al hombre un horizonte de seguridad y arraigo. Hay una nueva comprensión simbólica y semántica que combina lo nuevo y lo antiguo. Es una situación de intermedianidad esférica de inmunización que le permite al hombre continuar en el espacio del entre, es decir, con otros, habitando el mundo y ampliando su horizonte de existencia. De esta forma se abre el mundo y se clarifican espacios antes ocultos. "Siempre que situaciones nuevas y de emergencia requieren ser comprendidas y configuradas, los hombres recurren a rutinas de la situación anterior, relativamente íntegra, y la transportan al espacio extraño" (Sloterdijk, 2011, p. 136). No es, pues, una situación de adaptación, sino de formalización, de configuración de mundo, de hacer el nuevo espacio, un nuevo hogar, es un mecanismo de domesticación. De ahí la denominación de transferencia, pues se traen, se traducen, esto es, se transfieren los hábitos antiguos, se modifican en algunos aspectos, y se establecen como un nuevo orden inmunizado. Aquí es cuando el lenguaje cobra la mayor importancia en la fantasía filosófica sloterdijkiana. El lenguaje no solo aproxima el mundo en los actos de nombrar, narrar y comunicar, sino que transforma (transfiere) lo extraño en familiar y doméstico. "El lenguaje hace vivible la exposición humana al mundo abierto traduciendo los éxtasis en enstasis” (Sloterdijk, 2011, p. 137), 
esto es, hace cercano lo que antes era extraño y amenazante y también puede lograr, si esta es la intención, el efecto contrario, convertir lo doméstico en no doméstico. Por ello, para Heidegger el lenguaje era la poesía de la cercanía, de la patria, del hogar, de la casa, del ser.

\section{De la alotécnica a la homeotécnica}

Ya Desde Nietzsche habíamos Reconocido que el ser humano no tiene otra forma de estar en el mundo que técnicamente y que esos mecanismos de domesticación, es decir, esas antropotécnicas, no son ni mucho menos aleatorios con respecto al hombre, sino que esas prácticas constituyen el modo como el hombre cría a otros y a sí mismo. Con el anuncio de la muerte Dios, en un primer momento en Hegel, y con mayor fuerza en la obra de Nietzsche, nos hemos quedado al descubierto, es decir, expuestos, en medio de una orfandad difícil de asimilar. Ante esta situación de orfandad del hombre contemporáneo, Sloterdijk (2000), siguiendo las intuiciones filosóficas de Heidegger, se pregunta en "Reglas":

¿[q]ué amansará al ser humano, si, después de todos los experimentos que se han hecho con la educación del género humano, sigue siendo incierto a quién o a qué educa o para qué el educador? ¿O es que la pregunta por el cuidado y el modelado del hombre ya no se puede plantear de manera competente en el marco de unas simples teorías de la domesticación y de la educación? (p. 199).

Si bien es cierto que la educación hoy en día no puede continuar asumiendo el papel de domesticar al hombre, debe haber otro mecanismo humano que le permita aun en medio de tanta desolación configurar un mundo para él. Sloterdijk encuentra que ese medio es esencial al hombre y se da solo en la técnica moderna de finales del siglo XX y principios del XXI. Ya no solo hablamos de la posibilidad de la técnica nuclear de mitad del siglo XX, sino también y sobre todo de la técnica genética y la clonación de finales de siglo y que hoy atraviesa todas las prácticas de "cuidado" humanas.

Frente al fracaso del humanismo y de su tarea de domesticar al hombre, Sloterdijk piensa las circunstancias actuales que envuelven nuestro mundo desde un horizonte distinto que él denomina el hombre operable. "La noción hombre 
operable alude a una cierta condición antropobiológica” (Méndez, 2013, p. 181). Pensar al hombre implica verlo desde su desarrollo técnico y descubrir las implicaciones esenciales que esto acarrea para entender al homo humanus en una sociedad acelerada, tecnificada, sobresaturada de información y ajena a toda meditación juiciosa sobre las circunstancias del hombre en el mundo. Hay información. Es necesario repensar al hombre desde su proceso biocultural, lo que implica acercarnos a los avances biológicos históricamente determinados, abandonando con ello la idea absurda de una esencia del hombre que sostenían los humanismos previos a Heidegger. Ya no es posible un humanismo clásico, sino a lo mucho un posthumanismo con connotaciones distintas que Sloterdijk llama ser operable.

Aunque Sloterdijk sigue a Heidegger, no es para ser un fiel y dócil discípulo suyo aludiendo a sus metáforas pastoriles del hombre como pastor del ser, sino para rescatar de las intuiciones heideggerianas aquello que nos permite comprender mejor el mundo tecnificado al cual nos enfrentamos. Frente a la errancia y falta de hogar heideggerianas, Sloterdijk afirma que esta errancia y esta exposición son solo una transición de la antigua alotécnica a una homeotécnica ligada a la tecnología genética actual y a la co-inteligencia o, si se quiere, a un uso más humano de la técnica más allá de las categorías de dominio violento. En la alotécnica prevalece el modelo dialéctico metafísico amo-esclavo, sujeto-objeto (yo-materia) en la que se ve a la naturaleza como materia prima -incluyendo al ser humano- que se puede controlar y manipular según una subjetividad baja; y es precisamente esta idea de la tecnología lo que provoca un temor y una histeria colectiva en el mundo tecnológico. Es decir, provoca una actitud antitecnológica irracional. No obstante, es posible cambiar nuestra mirada histérica y reconocer una mejora moral con respecto a nuestras relaciones con los otros mediadas por la técnica. Se seguiría una mejora no solo técnica, sino ética. Esta situación es un problema de comprensión de fenómenos sobre los cuales no tenemos distancia; tenemos que esperar aún que pase el tiempo para dar razón suficientemente sobre sus causas y consecuencias sobre la existencia humana. Estamos tan cerca de los fenómenos de la tecnología actual que no logramos comprender su magnitud. Por ello, Sloterdijk propone la noción de homeotécnica, que le permite al filósofo de Karlsruhe abandonar el rastro metafísico de las comprensiones anteriores, incluyendo al mismo Heidegger, y expresar mejor la nueva relación entre ser humano-información-naturaleza. Dicha relación es de una complejidad 
enorme, sobre todo si tenemos en cuenta la exorbitante información de la cual disponemos a tan solo unos cuantos clics, sin necesidad de salir de nuestra casa.

Así, la homeotécnica nos permite pensar esta relación que propiciará la creatividad y la innovación como nuevas formas de relación, completamente alejadas de la dialéctica moderna de amo-esclavo (Guzmán, 2012, p. 1). El asunto aquí es de una argumentación juiciosa y difícil, pues no solo nos aparta de la tradicional mirada de horror frente a los avances tecnológicos, sino que nos conduce a pensar una mejora moral si se hace uso adecuado de dichas tecnologías genéticas. Todo esto porque hoy no podemos ya distinguir entre lo natural y lo artificial, sino que nuestro mundo es el mundo artificial tecnológicamente configurado, modificado y determinado, que promete en este siglo o en el próximo una mejora no solo antropotécnica, sino también ético-moral. Hoy ya no cabe continuar con una interpretación (humanista) del mundo estructurada sobre la dicotomía sujeto-objeto, porque "los hombres necesitan relacionarse entre ellos, pero también con las máquinas, los animales, las plantas [...], y deben aprender a tener una relación polivalente con el entorno" (Sloterdijk, 2013, p. 5). En nuestro presente disponemos de entidades que superan el dualismo moderno yomateria. De esta forma, podemos notar que el verdadero desafío de nuestro filósofo es pensar el estatuto ontológico de elementos con los cuales cohabitamos diariamente y cuyo efecto sobre nosotros difícilmente comprendemos. En esta pequeña conferencia sobre el hombre operable apenas se introduce el desafío de la homeotécnica, como un concepto positivo ante la histeria antitecnológica en boga en el mundo occidental.

El diagnóstico de esta conferencia es clave para entender la obra posterior de Sloterdijk, pues lo que piensa es la reconfiguración de un mundo donde la casa del ser heideggeriana desaparece, ya que, en palabras del mismo Sloterdijk (2011), "la vieja casa del ser aparece como algo en lo que apenas es aún posible una estancia en el sentido del habitar o del hacer próximo lo lejano" (p. 138). Esto quiere decir que los primitivos mecanismos de domesticación y de acercamiento de lo extraño, de las amenazas del exterior del entorno, ya no nos permiten domesticar los elementos emergentes con los cuales cohabitamos y que no hemos podido catalogar, ni tan siquiera nombrar. De esta forma el lenguaje parece quedarse corto ante la realidad: "la cultura técnica lleva al lenguaje y la escritura a un nuevo estado que poco tiene en común con las interpretaciones 
tradicionales que de ellos han hecho la religión, la metafísica y el humanismo" (Sloterdijk, 2011, p. 138). Se hace necesario comprender cuáles son los nuevos mecanismos de domesticación, si esto aún es posible, con los cuales vivimos hoy y no podemos identificar por estar nosotros mismos inmersos en ellos.

La reflexión sloterdijkiana sigue pensando las posibles técnicas de domesticación apartándose de la alotecnología y su reduccionismo sujeto-objeto que caracterizaba el errar metafísico:

Si se busca motivaciones más profundas para este "errar" de la humanidad histórica, se descubre una de ellas en las circunstancias de que los actores de la era metafísica hicieron de la totalidad de lo ente una descripción manifiestamente inadecuada. Ellos dividieron lo humano, de un lado, y lo cósico, lo mecánico, lo no humano, de otro (Sloterdijk, 2001, p. 143).

Hoy ya no es posible hablar de la mera domesticación del entorno, sino de la domesticación de aquellas realidades humanas que estaban ligadas a la intervención divina. "Toda nuestra ontología clásica es insuficiente para comprender entidades que superan la división dualista sujeto-objeto” (Vásquez, 2012, p. 128). Ya no solo dominamos la naturaleza, sino que dominamos genéticamente al ser humano mismo y en ello parece que el poder sobre el mundo y lo antaño familiar se nos escapa en una lógica de dominio de materias primas. Esta es la realidad presente de la domesticación del ser.

La biotecnología y la ingeniería genética [...] han abierto unas posibilidades de intervención que, de momento, están poniendo a prueba todos nuestros horizontes morales al depositar en nuestras manos un poder que siempre estuvo reservado a los dioses. En pocas palabras, la automanipulación del hombre, la homeotécnica, no son una posibilidad, son un hecho (González, 2005, pp. 5-6).

Estamos en un mundo en el cual el hombre se manipula y se configura a sí mismo, biológica, genética e históricamente. Heidegger lo intuyó, pero Sloterdijk lo asume y lo piensa para un mundo hoy. ¿Qué domesticará hoy al hombre si el humanismo ya no responde a las realidades biológicas e históricas de nuestro tiempo? ¿Hemos pensado suficientemente ya qué significa vivir en un mundo digital? ¿Qué implicaciones ontológicas tiene para el hombre la realidad del ciberespacio? ¿En su hacer técnico el hombre aún está morando en la casa del ser consigo mismo? 
Bajo esta mirada el estatuto ontológico de elementos con los cuales nos las vemos todos los días cambia, y también cabe plantearse la cuestión de si debemos volver a preguntarnos por el estatuto ontológico del hombre, ya que "todo lo que acontece en el frente de la técnica tiene consecuencias para la autoconcepción humana" (Sloterdijk, 2011, pp. 143-144). De ahí que la propuesta antropotécnica sloterdijkiana no sea para nada incoherente, pues está pensando cuál es el lugar que le queda al hombre en este mundo donde lo no-familiar, lo no-propio, parece ganarnos la partida. Debemos pensar cuál es la relación del hombre con el mundo de las máquinas, y ya no solo su relación con la naturaleza y los otros. "Asistimos a la era proteica, artificial, a los tiempos del devenir de los nuevos mutantes" (Vásquez, 2012, p. 128). Hay hombre, hay mundo, hay ser, hay máquinas, hay fármacos, hay drogas, hay información. ¿Qué significa que nos las veamos hoy necesariamente con las máquinas y los avances, no solo nucleares, sino sobre todo tecnogenéticos?

Sloterdijk enfrenta así los problemas de su tiempo como un fenomenólogo agudo, atento y perspicaz, que desea escribir una "ontología de nosotros mismos", que incorpora a sus observaciones todo aquello con lo que el hombre convive: signos, máquinas, animales, plantas, virus, bacterias, textos, obras de arte, museos, prótesis, intervenciones quirúrgicas, fármacos; a lo que se debe sumar la crisis del humanismo, la irrupción de la cibertecnología y el surgimiento del provincialismo global (Vásquez, 2013, p. 1).

Ante lo no-propio y la apatridad heideggeriana, Sloterdijk parece proponer un retorno a la casa, pero no ya la misma casa, ya no es la misma patria y nunca podrá ser la misma. No se queda en el errar del filósofo del Ser, sino que da un paso más y le apuesta a una comprensión del hombre y la técnica en una relación esencial, pues ya no se puede entender la subjetividad desligada de los avances tencnogenéticos. "También Heidegger, por innegable que sea su importancia como destructor de la metafísica, estuvo en parte preso en una gramática que tiene por supuesto una ontología simplemente insostenible y una lógica insuficiente" (Sloterdijk, 2011, p. 141). Así, una vez más podemos reconocer la mirada ontoantropotécnica del proyecto sloterdijkiano. "El filósofo alemán insiste, pues, en la auto-operabilidad como cura del destino nihilista de errancia del mundo contemporáneo. Así que uno no puede evitar divisar aquí el sueño de un cyborg 
posthumano, superador de la decadencia” (Vásquez, 2008, p. 2). Ante este panorama Sloterdijk piensa una comprensión de nuestra relación con lo artificial en la distinción entre "alotecnologías", que son dominadoras y violentan la naturaleza de las cosas, y "homeotecnologías", que serían una forma no-dominadora de operatividad que estaría surgiendo con las tecnologías inteligentes y que abrirían y de hecho están abriendo nuevas comprensiones del mundo que nos permita vivir en un mundo inevitablemente tecnocientífico.

Las viejas comprensiones no dan razón del presente y por ello debemos entrar en una revolución en nuestro mismo pensamiento. Hoy se demanda cambiar nuestra percepción de mundo y soltar las cadenas conceptuales dualistas con las cuales la filosofía se ha sentido cómoda por más de dos mil años. Sloterdijk nos pide incomodarnos un poco para entrar a pensar los asuntos serios de la relación humano-información-mundo. Nótese el acento que Sloterdijk le da a la información, pues ante el "hay ser y se da el ser" de Heidegger, Sloterdijk parece pensar el "hay información y se da la información".

Hoy ya no podemos comprender la diferencia entre humano y no humano independientemente, sino que lo que antes se tenía como extraño hace parte vital de nosotros gracias a las prácticas médicas y científicas de orden tecnológico y genético: "La ciencia médica ha introducido lo inhumano dentro de lo humano hace ya largo tiempo, piénsese en los marcapasos o las máquinas para diálisis, como ejemplos controvertidos de la conjunción entre hombre y la máquina" (Im, 2004, p. 15). Ya no solo vivimos con las máquinas, sino gracias a las máquinas. La histeria actual de rechazo de las tecnologías emergentes, que hoy atraviesan casi todas las relaciones humanas, es una histeria de incomprensión del lugar del hombre en su mundo. Es una histeria que busca permanecer en una relación amo-esclavo (alotécnica) de la antigua metafísica al modo hegeliano", que no permite entender la propuesta homeoténica de cohabitación y cooperación con los avances tecnológicos tal como efectivamente lo estamos viviendo en pleno siglo XXI. "La histeria es de hecho la búsqueda de un amo contra el que poder rebelarse” (Sloterdijk, 2011, p. 146). Sin embargo, por nuestra incapacidad de soltar viejos sistemas conceptuales, no podemos vivir mejor con las tecnologías

9 Aunque cabe anotar que Hegel trató de pensar el asunto en su llamado espíritu objetivo. 
creadas por nosotros mismos. Solo si comprendemos nuestra verdadera relación con las tecnologías, podemos entender mejor la propuesta antropotécnica de Sloterdijk y su mirada sobre el mundo de hoy, ese mundo que amenaza con llevarnos a un rechazo irracional de lo que ha salido de nuestras propias manos y que nos autoconfigura, nos automodela, nos autodomestica.

De esta forma podemos comprender que la reflexión sloterdijkiana sobre el claro, partiendo de las lúcidas intuiciones heideggerianas, nos han conducido a pensar nuestro presente aclarado en una relación fundamental del hombre-técnica y las implicaciones ontológicas que de estas realidades se desprenden.

Pensar el homo humanus significa, como hemos dicho, mostrar abiertamente el plano en que rige la ecuación de ser humano y claro. Pero claro no puede pensarse, como ahora sabemos, sin su origen tecnógeno. El hombre no está en el claro con las manos vacías, cual pastor vigilante y sin recursos junto al rebaño, como sugieren las metáforas pastoriles de Heidegger (Sloterdijk, 2011, p. 146).

El hombre dispone desde su origen, como veíamos a lo largo del ensayo, de piedras, que devinieron herramientas y hoy manipulación genética, marcapasos, celulares, computadores, etc., con los cuales nos las vemos todos los días y sin los cuales el mundo humano no sería posible. Por ello en la comprensión posthumanista sloterdijkiana de la humanitas solo puede pensarse con sus vínculos con la técnica y los resultados que de ellas se desprendan. "La historia de la hominización camina de la mano con la historia de los dispositivos tecnológicos” (Méndez, 2013, p. 184). Así, pasamos de la piedra al mundo digital, del manejo de herramientas a instrumentos que se operan con las yemas de los dedos, lo que cambia completamente lo que hemos entendido hasta ahora como actuar en el mundo y, por ende, nuestro estar-en-el-mundo.

\section{Referencias}

Borch, C. (2013). Spaciality, Imitation, Immunization: Luhmann and Sloterdijk on the Social. En: A. la Cour (Ed.). Luhmann Observed. Radical Theoretical Encounters (pp. 150-170). New York: Palgrave Macmillan. 
Bordeleau, E. (2007). Entre biopouvoir plastique et biopolitique de la sélection: Sloterdijk penseur de l'anthropogénétique. Altérités, 4(2), 92-107.

Bühlmann, V. (2007). Peter Sloterdijk's Phantastic Philosophy. Taking the Concept of the Differential as a Relational Measure. Recuperado de http://www. caad.arch.ethz.ch/blog/wp-content/uploads/2008/01/NotreDame_Buehlmann_April2010.pdf

Cassirer, E. (1967). Antropología filosófica. Introducción a una filosofía de la cultura. México: Fondo de Cultura Económica.

Castro-Gómez, S. (2012). Sobre el concepto de antropotécnica en Peter Sloterdijk. Revista de Estudios Sociales, (43), 63-73.

Derrida, J. (1995). Dar (el) tiempo. Barcelona: Paidós.

Gehlen, A. (1993). Antropología filosófica. Del encuentro y descubrimiento del hombre por si mismo. Barcelona: Paidós.

González, A. (2005). El humanismo a debate. Recuperado de http://filoantropologia.webcindario.com/humanismodebate.pdf.

Guzmán, J. (2012). El hombre operable. Notas sobre el estado ético de la tecnología génica. Recuperado de https://ctsimexico.wordpress. com/2012/05/02/hombre-operable/

Heidegger, M. (2000). Carta sobre el humanismo. Madrid: Alianza Editorial.

Im, S. (2004). Lyotard y lo inhumano. Barcelona: Editorial Gedisa.

Jacques, D. (2007). Fin et retour de l'humanisme: De la domestication de Heidegger par Sloterdijk. Horizons Philosophiques, 17(2), 21-43.

Jongen, M. (2011). On Anthropospheres and Aphrogrammes. Peter Sloterdijk's Thought Images of the Monstrous. Humana.Mente - Journal of Philosophical Studies, 18, 199-219.

Méndez Sandoval, C. (2013). Peter Sloterdijk: pensar al hombre en una época posthumanista. Revista Guillermo de Ockham, 11(2), 173-185.

Mussi, S. (2007). Préludes à Sphères. L'amorce du grand récit fantastique de Peter Sloterdijk: Une lecture de La domestication de l'Être. Horizons philosophiques, 17(2), 45-59.

Pipó Comorera, J. (2003, mayo). ¡Que viva la deshumanización! En IV Seminario. La deshumanización del mundo. Estancias de reflexión en torno a la crisis del humanismo, organizado por Arteypensamiento de la Universidad Internacional de Andalucía. Sevilla, España. 
Nietzsche, F. (2003). Asi habló Zaratustra. Madrid: Alianza Editorial.

Scheller, M. (1994). El puesto del hombre en el cosmos. Buenos Aires: Editorial Losada.

Sloterdijk, P. (2003). Esferas. Madrid: Siruela.

Sloterdijk, P. (2005). El post-humanismo: sus fuentes teológicas, sus medios técnicos. En IV Seminario. La deshumanización del mundo. Estancias de reflexión en torno a la crisis del humanismo, organizado por Arteypensamiento de la Universidad Internacional de Andalucía. Sevilla, España.

Sloterdijk, P. (2006). En el mismo barco. Ensayo sobre la hiperpolítica. Madrid: Ediciones Siruela.

Sloterdijk, P. (2011). Sin salvación. Tras las huellas de Heidegger. (Trad. J. Chamorro Mielke). Madrid: Akal.

Teyssot, G. (2013). A Topology of Everyday Constellations. Cambridge, MA: MIT Press.

Tuinen, S. (2011). Air Conditioning Spaceship Earth: An Ethico-Aesthetic Paradigm. Society and Space, 27(1), 105-118.

Vásquez Rocca, A. (2009a). Sloterdijk, Agamben y Nietzsche: biopolítica, posthumanismo y biopoder. Nómadas. Revista Crítica de Ciencias Sociales y Jurídicas, 23(3), 1-12.

Vásquez Rocca, A. (2009b). Sloterdijk y Heidegger: humanismo, deshumanización y posthumanismo en el parque humano. Konvergencias. Filosofía y Culturas en Diálogo, (20), 191-204.

Vásquez Rocca, A. (2012). En torno al diseño de lo humano en Sloterdijk: De la ontotecnología a las fuentes filosóficas del posthumanismo. La Lámpara de Diógenes. Revista de Filosofia, (24-25), 127-140.

Vásquez Rocca, A. (2013, agosto). Ontotecnología del cuerpo en Jean-Luc Nancy y Sloterdijk: Alteridad, subjetivación y apostasía de los órganos. Rosebud. Arts, Critique, Journalism. Recuperado de http://rinabrundu. com/2013/08/10/ontotecnologia-del-cuerpo-en-jean-luc-nancy-y-sloterdijk-alteridad-subjetivacion-y-apostasia-de-los-organos/

Zin, J. (2014). La domestication de l'Être, Peter Sloterdijk. Recuperado de http:// jeanzin.fr/ecorevo/philo/sloterdi.htm 